\title{
Influence of Sr addition on microstructure of the hypereutectic $\mathrm{Zn}-\mathrm{Al}-\mathrm{Cu}$ alloy
}

\author{
M. Krupiński ${ }^{1}$ M. Król ${ }^{1}$ (ib) B. Krupińska' $\cdot$ K. Mazur ${ }^{1} \cdot$ K. Labisz ${ }^{2}$
}

Received: 4 December 2017 / Accepted: 19 May 2018/Published online: 4 June 2018

(C) The Author(s) 2018

\begin{abstract}
The purpose of the presented work is to answer the questions: how does the addition of strontium to the $\mathrm{Zn}-8 \mathrm{Al}-1 \mathrm{Cu}$ alloy crystallisation kinetics influence? What will the significance of the low temperature of heat treatment, characteristic for eutectic $\mathrm{Zn}-\mathrm{Al}$ alloys, have for the formation of intermetallic phases? To describe the phenomena that occur in the metal during solidification under various conditions caused by the variable cooling rate, and as a result of the application of modifiers that provide the basis for heterogeneous nucleation, it was decided to use thermal-derivative analysis method. The mentioned method allows to accurately describe and interpret the kinetics of crystallisation of the tested materials. The effectiveness of the modification was assessed based on a degree of fragmentation of the structural components and changes in the properties of the material being modified, as well as by analysis of the cooling curves of the tested alloys. The thermal events occurring during solidification process, i.e. liquidus $\left(T_{\mathrm{L}}\right)$ and solidus $\left(T_{\mathrm{Sol}}\right)$ temperatures and the beginning of phases and eutectic nucleation, were determined with the thermal-derivative analysis and calculation of total heat of crystallisation of the analysed material.
\end{abstract}

Keywords Zinc alloys · Microstructure - Thermos-derivative analysis · Crystallisation kinetics · Phase composition

\section{Introduction}

The processes that occur during crystallisation and phase transitions are most conveniently analysed by phase equilibrium systems that describe the effect of the type, quantity, composition and temperature on the microstructure of the alloys. For this purpose, it is necessary to consider a hypothetical system, isolated from the environment, i.e. a system for which no external forces are active; and between it and the environment no energy exchange takes place in any form [1].

The authors of the work describe in particular the effect of crystallisation conditions on the properties of the obtained zinc alloys. The significant influence on the

\section{Król}

mariusz.krol@polsl.pl

1 Institute of Engineering Materials and Biomaterials, Faculty of Mechanical Engineering, Silesian University of Technology, Konarskiego St. 18a, 44-100 Gliwice, Poland

2 Faculty of Transport, Silesian University of Technology, Krasinskiego St. 8, 40-019 Katowice, Poland mechanical properties of zinc castings also has the pouring temperature, which is even confirmed by Yang et al. [2]. The best tensile strengths were obtained for the hypoeutectic $\mathrm{Zn}-\mathrm{Al}$ alloys with a content of $4.6 \% \mathrm{Al}$ at the temperature of isothermal holding at $460{ }^{\circ} \mathrm{C}$ before the casting process. Moreover in work [3] was shown the significant effect of the solidification time on the properties of the ZL3 alloy. In these studies were used for investigation a solidstate flow analysis method and the virtual Garcia model to determine the solidification interval of the casting. It has been found that an increase in the cooling rate decreases the casting density as well as the yield point of the melt.

Durman et al. show the results of microstructure investigations resulting from phase transformations that occur in $\mathrm{Zn}-\mathrm{Al}$ alloys containing $\mathrm{Cu}$ and $\mathrm{Si}$ additives [4]. Two metastable phases: $\eta^{\prime} S$ and $\eta^{\prime} E$ have been identified. The dissolution of $\mathrm{Cu}$ and $\mathrm{Al}$ in the $\mathrm{Zn}$-rich phase $\eta$ results in a change in crystalline structure parameters, which affects physical and mechanical properties, and in particular dimensional stability of the alloy.

The solidification of the hypereutectic alloy with a much higher Al mass concentration (ZA27) starts with the 
solidification of the $\alpha$ phase dendrites, and then as a result of the peritectic transformation are produced grains of the $\beta$ phase around the edge of the $\alpha$ phase. The increase in cooling rate during solidification decreases the range of occurrence of the peritectic reaction, causing enrichment of the liquid phase in $\mathrm{Zn}$ and solidification of the $\beta+\eta$ eutectic. As a result of rapid cooling, at the transition temperature of the eutectoid transformation occurs a transformation of the $\beta$ phase into partially transformed irregular phase precipitation $\alpha^{\prime}$ and $\eta$. In the eutectic transformation, the addition of copper limits the degradation of metastable phases. After the melt has been solidified, copper with zinc forms the $\mathrm{Zn}_{4} \mathrm{Cu}$ phase present in areas of the dendrite inter arms, while the remainder of copper dissolves in the $\eta$ phase with a particle size of $70-120 \mathrm{~nm}$ and thickness of 2-3 nm [5]. The mentioned two papers deal with the role of commonly used Ti-based particles as substrates of the heterogeneous nucleation in $\mathrm{Zn}-\mathrm{Al}$ alloys, while these authors discuss the similar role of the $\mathrm{Al}_{4} \mathrm{Sr}$ and $\mathrm{Al}_{2} \mathrm{Sr}$ phases [6].

To describe the phenomena that occur in the material during the freezing conditions caused by variable cooling speed, but also as a result of the application of the modifiers, which are ground to heterogeneous nucleation, the methods for thermal-derivation analysis were used. The way as mentioned above allows accurately describing and interpreting the crystallisation kinetics of the tested materials. This method allows determining the relationship between the crystallisation kinetics and properties of zinc alloy casting with aluminium and copper both unmodified and modified with strontium to obtain zinc-aluminium alloy with more favourable and stable usage properties.

\section{Experimental}

The investigations were performed on laboratory-prepared $\mathrm{Zn}-\mathrm{Al}-\mathrm{Cu}$ cast alloys, to which a suitable amount of alloying element was introduced in the form of $10 \% \mathrm{Al}-\mathrm{Sr}$ master alloy. The chemical composition is given in Table 1.

The investigated alloys were heated to $700{ }^{\circ} \mathrm{C}$ and then isothermal held at this temperature for $180 \mathrm{~s}$ and then

Table 1 Chemical composition of $\mathrm{Zn}-\mathrm{Al}-\mathrm{Cu}$ cast alloy

Mass concentration of the element/mass $\%$

\begin{tabular}{lrlll}
\hline & $\mathrm{Al}$ & $\mathrm{Cu}$ & $\mathrm{Sr}$ & Rest \\
\hline $\mathrm{Zn}-\mathrm{Al}(1 \mathrm{Sr})$ & 8.51 & 0.93 & 1.02 & $\mathrm{Zn}$ \\
$\mathrm{Zn}-\mathrm{Al}$ & 10.02 & 0.98 & - & $\mathrm{Zn}$ \\
\hline
\end{tabular}

cooled. The alloy was also melted at $460{ }^{\circ} \mathrm{C}$, and the results were described in [7].

The thermal analysis of the tested alloys was performed on a UMSA MT5 platform. That platform was also used for testing other non-ferrous metal alloys such as aluminium, magnesium or copper, giving to engineers information about crystallisation process, i.e. temperatures of transitions in liquid or solid state, solidification interval, solidification sequence or latent heat.

The samples prepared for the thermal tests of $\varnothing 30 \times 35 \mathrm{~mm}$ were made from the previously produced ingots and were then melted in graphite crucibles.

The thermocouples were placed in the same location (thermal node), which was determined at the initial tests of ZL8 alloy according to the PN-EN 1774 standard. For slowly cooled samples (for a predetermined system and mass of the examples), the cooling rate was about $0.1{ }^{\circ} \mathrm{C} \mathrm{s}^{-1}$ and a protective atmosphere was used in the form of a compressed gas (argon) supplied through nozzles located in the heating coil. The flow rate of the flowing gas was regulated by a rotameter in which the UMSA is equipped. The applied thermal programme was:

- isothermal holding temperature of the liquid $=460$ and $700{ }^{\circ} \mathrm{C}$,

- isothermal holding time $=180 \mathrm{~s}$.

The test samples were cut in a plane passing through the middle of the ingot. The prepared samples were then etched in following reagents: $10 \% \mathrm{HF}$ and $10 \mathrm{~g} \mathrm{CrO}_{3}$ $+1 \mathrm{~g} \mathrm{Na}_{2} \mathrm{SO}_{4}+200 \mathrm{~mL} \mathrm{H} \mathrm{H}_{2} \mathrm{O}$ and then cleaned in $40 \mathrm{~g}$ $\mathrm{CrO}_{3}+200 \mathrm{~mL} \mathrm{H} \mathrm{H}_{2} \mathrm{O}$. The etching time and reagent concentration were selected experimentally separately for each of the test alloys. Metallographic analyses were performed using the Leica MEF 4A metallographic microscope, as well as Zeiss Axio Observer, Olympus LEXT OLS4000, using a computer image analysis system with magnifications in the range of 50-500 times.

Qualitative and quantitative X-ray microanalysis and chemical area element analysis of the alloying elements (mapping) were performed on samples in the form of crosscuts to the casting direction using the Oxford EDS LINK ISIS X-ray diffraction spectrometer at $15 \mathrm{kV}$ accelerating voltage as well as using the JEOL JCXA 733 $\mathrm{X}$-ray microanalysis.

As a result of the carried-out investigations concerning the surface mapping of the elements in the cooled alloys with the determined cooling rates assumed in the experimental plan using the EDS spectrometer and point analysis performed with the WDS wavelength spectrometer, the differences in the chemical distribution were determined in terms of the crystallisation process of the phases that occurred in the alloy related to specified cooling conditions. 
Microstructure investigations of thin films and precipitation phase identification were carried out using JEOL 3010CX transmission electron microscope (TEM) and Titan 80-300, using SAD electron diffraction (Selected Area Diffraction) at $300 \mathrm{kV}$ acceleration voltage, to identify the crystalline phase structures. The obtained diffraction patterns were analysed by specialised software dedicated to solving electron diffraction patterns.

Abrasion resistance tests were performed using a ballon-plate tribometer, in which a steel ball $6 \mathrm{~mm}$ in diameter in a reciprocating movement modus has carried out measurements on the surface of the specimens with a maximum surface roughness $\mathrm{Ra} 0.1$ at a velocity of $4 \mathrm{~cm}^{-1}$ at $10 \mathrm{~N}$ pressure. The total friction path was $50 \mathrm{~m}$.

\section{Results and discussion}

As a result of the thermal-derivative analysis were determined the characteristic temperature values of the crystallisation of individual phases and the eutectic during the cooling of the melt (Fig. 1 and Table 2).

The analysis shows that these are significant grains of very fine eutectics, where the term "grain" describes the area of the structure of individually arranged, parallel and fragile plates $\alpha^{\prime}$ and $\eta$. Grains of a very fine "eutectic" formed in the remaining areas of primary phase $\alpha$, which have been created based on the eutectoidal transformation (Fig. 2). The difference in the structure after the monotectic and eutectoidal transformation results from the diffusion velocity in the solid phase and the liquid phase. Therefore, the narrower the edge area of a medium-grained eutectic structure around the interior of the primary $\alpha$ grains, the higher the cooling rate, which prevents diffusion into the primary $\alpha$ particles and the rest of the grain interior should decay without reacting phase $\alpha$ with phase $\eta$.

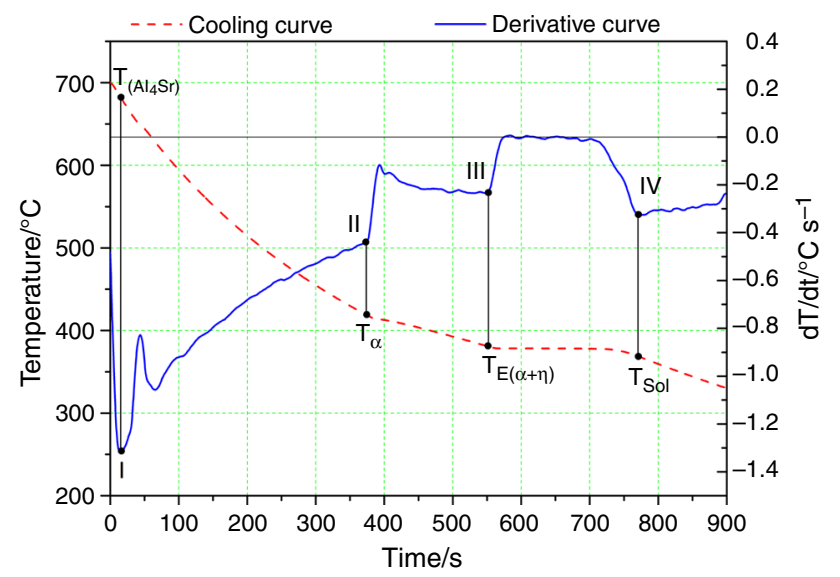

Fig. 1 Cooling curve and derivative curve of the $\mathrm{Zn}-\mathrm{Al}$ alloy with $\mathrm{Sr}$ addition cooled at a rate of $0.1{ }^{\circ} \mathrm{C} \mathrm{s}^{-1}$
Table 2 Characteristic temperature of the individual stages of the phase transformation process during the crystallisation of the investigated alloys

\begin{tabular}{lllll}
\hline Alloy type & \multicolumn{4}{l}{ Temperature $/{ }^{\circ} \mathrm{C}$} \\
\cline { 2 - 5 } & $T_{(\mathrm{Al} 4 \mathrm{Sr})}$ & $T_{\alpha(\mathrm{Al})}$ & $T_{\mathrm{E}}$ & $T_{\text {Sol }}$ \\
\hline $0.1{ }^{\circ} \mathrm{C} \mathrm{s}^{-1}$ & & & & \\
$\mathrm{Zn}-\mathrm{Al}$ & - & 414.5 & 381.2 & 372.7 \\
$\mathrm{Zn}-\mathrm{Al}(1 \mathrm{Sr})$ & 657.8 & 413.9 & 381.1 & 377.3 \\
\hline
\end{tabular}

$T_{\text {(Al4Sr) }}$, beginning of nucleation of $\mathrm{Al}_{4} \mathrm{Sr}$ phase; $T_{\alpha(\mathrm{Al})}$, liquidus temperature; $T_{\mathrm{E}}$, solidification temperature of the eutectic $\eta+\alpha ; T_{\mathrm{Sol}}$, solid temperature

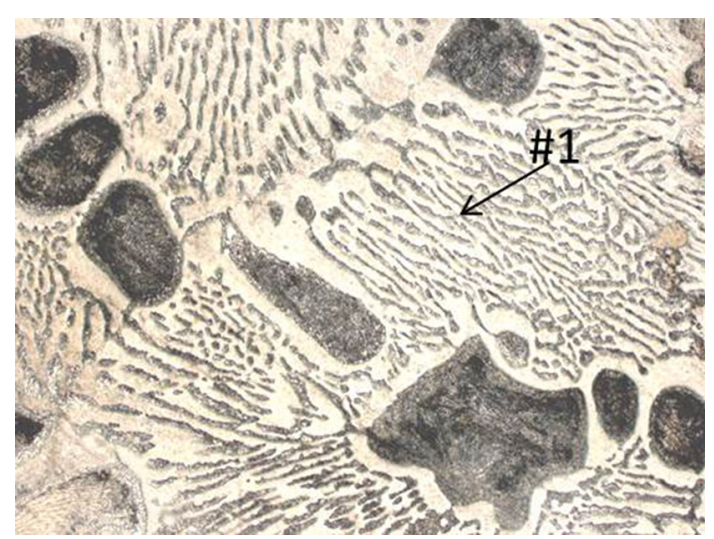

Fig. 2 The microstructure of the $\mathrm{Zn}-\mathrm{Al}$ alloy, a cooling rate $0.1^{\circ} \mathrm{C} \mathrm{s}^{-1}$, "fine eutectic" $\alpha^{\prime}$ and $\eta$; \#1-eutectic $\alpha^{\prime}+\eta$

The performed metallographic analysis of strontiummodified $\mathrm{Zn}-\mathrm{Al}-\mathrm{Cu}$ alloys confirms the significant change in the morphology of the "fine eutectic" precipitations, which also occur in the form of large globular precipitates. Moreover, light microscopy studies revealed the occurrence of the $\mathrm{Al}_{2} \mathrm{Sr}$ and $\mathrm{Al}_{4} \mathrm{Sr}$ phases $[8,9]$ occurring partially in a quasi-spherical shape and/or angular precipitates with straight edges (Fig. 3).

Based on the chemical composition investigations of the individual structural components in the cast $\mathrm{Zn}-\mathrm{Al}$ and $\mathrm{Zn}-$ $\mathrm{Al}(1 \mathrm{Sr})$ alloys (Fig. 4), no differences in the phase composition of the alloys tested were found. However, the effect of cooling rate on the change in morphology of precipitates was observed, especially the morphology of "fine eutectics" ( $\alpha^{\prime}$ and $\eta$ ), and $\alpha^{\prime}+\eta$ eutectics.

Investigations of the $\mathrm{Zn}-\mathrm{Al}-\mathrm{Cu}-\mathrm{Sr}$ alloy structure using transmission electron microscopy (TEM) confirmed the presence of the $\alpha^{\prime}+\eta$ eutectic, which was also approved by the chemical composition (Fig. 5 and Table 3). Studies have confirmed that strontium does not occur in the entire volume of the analysed samples. However, in areas where it presents, it happens in a relatively homogeneous concentration. 
Fig. 3 Microstructure of the $\mathrm{Zn}-\mathrm{Al}(1 \mathrm{Sr})$ alloy, cooling rate $0.1{ }^{\circ} \mathrm{C} \mathrm{s}^{-1}, \# 1-\mathrm{Al}_{4} \mathrm{Sr}:$ a $10 \%$ $\mathrm{HF}, \mathbf{b} 10 \mathrm{~g} \mathrm{CrO}_{3}+1 \mathrm{~g}$ $\mathrm{Na}_{2} \mathrm{SO}_{4}+200 \mathrm{~mL} \mathrm{H} \mathrm{H}_{2} \mathrm{O}$ cleaned in $40 \mathrm{~g}$ $\mathrm{CrO}_{3}+200 \mathrm{~mL} \mathrm{H} \mathrm{H}_{2} \mathrm{O}$ \#1$\mathrm{Al}_{4} \mathrm{Sr}$ (a)

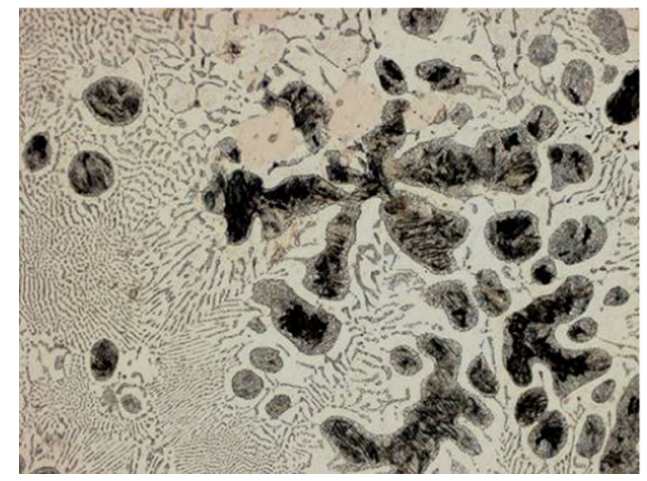

(b)

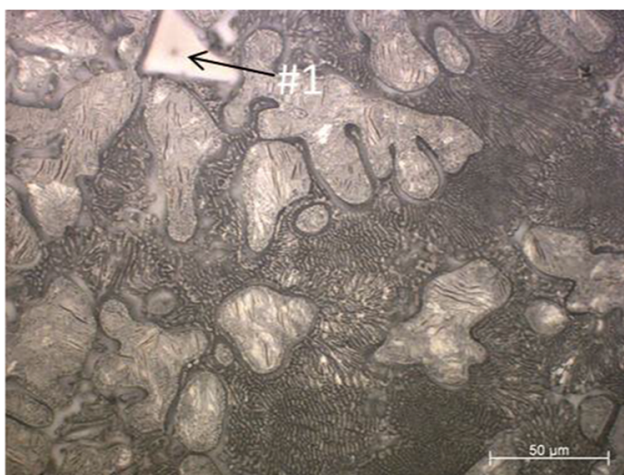

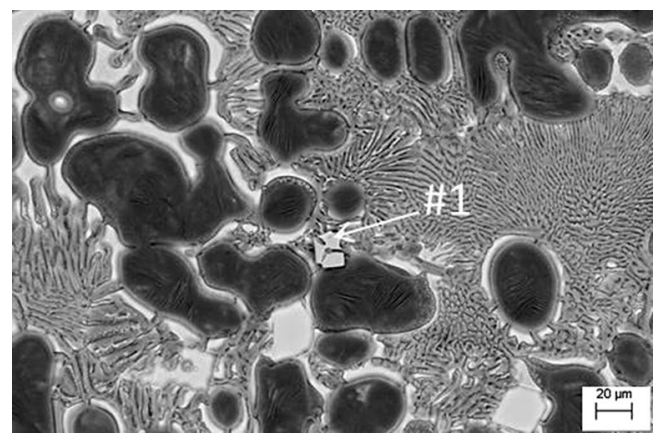

Fig. 4 The microstructure of the cast $\mathrm{Zn}-\mathrm{Al}(1 \mathrm{Sr})$ alloy cooled with a rate of $0.1{ }^{\circ} \mathrm{C} \mathrm{s}^{-1}$; EDS microanalysis performed in point $\# 1$ in mass\%: Al 5.6; Zn 67.1; Cu 2.1; Sr 25.2

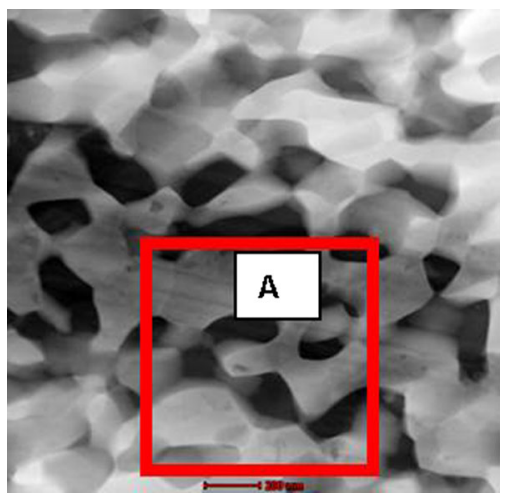

Fig. 5 The microstructure of the $\mathrm{Zn}-\mathrm{Al}-\mathrm{Cu}$ alloy modified with $\mathrm{Sr}$ cooled with a rate of $0.1{ }^{\circ} \mathrm{C} \mathrm{s}^{-1}, \mathrm{Zn}-\mathrm{Al}$ eutectic

Table 3 Quantitative EDS micro analysis results performed in place presented in Fig. 5 point A

\begin{tabular}{lcc}
\hline Element & Mass concentration/\% & Atomic concentration/\% \\
\hline $\mathrm{O}$ & 5.1 & 15.4 \\
$\mathrm{Al}$ & 12.6 & 22.9 \\
$\mathrm{Cu}$ & 0.6 & 0.4 \\
$\mathrm{Zn}$ & 81.6 & 61.1 \\
\hline
\end{tabular}

To perform a complex identification of the structural components of the $\mathrm{Zn}-\mathrm{Al}(1 \mathrm{Sr})$ alloy, electron diffraction investigations were conducted which confirmed the presence of both the $\mathrm{Al}_{2} \mathrm{Sr}$ and $\mathrm{Al}_{4} \mathrm{Sr}$ phases (Fig. 6). The meltparticle morphology of strontium in most cases reveals a globular form of up to $20 \mu \mathrm{m}$.

During the melting of the alloy with the addition of $\mathrm{Sr}$ at $700{ }^{\circ} \mathrm{C}$ in phase, the composition is $\mathrm{Al}_{2} \mathrm{Sr}$ primary phase, secondary phase and phase $\mathrm{Al}_{4} \mathrm{Sr} \alpha^{\prime}$ and eutectic $\alpha^{\prime}+\eta$ after transformation. This is confirmed by the studies of DTA (Fig. 1) and the analysis of the chemical and phase composition. In the case of melting the alloy at a temperature of $460{ }^{\circ} \mathrm{C}$ occur primary $\mathrm{Al}_{4} \mathrm{Sr}$ and $\mathrm{Al}_{2} \mathrm{Sr}$ phases. In contrast, part of strontium already at this temperature goes into solution (although the melting temperature of phase $\mathrm{Al}_{4} \mathrm{Sr}$ is a much higher temperature) and forms a phase $\mathrm{Zn}_{13} \mathrm{Sr}$ (according to the layout balance of $\mathrm{Zn}-\mathrm{Sr}$ ), which is confirmed by the preliminary study.

Additive of $\mathrm{Cu}$ is dissolved in the eutectic phase and does not form $\varepsilon$. This is also confirmed in a study [10] despite the increased mass concentration of $\mathrm{Cu}$. The same alloy examined after 1.5 years of natural ageing has the metastable $\varepsilon$-phase $\mathrm{CuZn}_{4}$ in its structure [10].

Figure 7 shows an image trace image made using a confocal microscope that provides a high depth of field and the ability to evaluate the height of a surface image (colour scale).

Figure 6a shows deposition of material above the surface of the test sample (red) and cavity (dark blue) formed by the reciprocating movement of the steel ball. Alloys with strontium addition, despite a few per cent reductions in mass and volume loss after the wear test (Table 4), have been more uniformly worn throughout the entire friction path, indicating an increased uniformity of decomposition of the fine-grained hard $\mathrm{Al}_{2} \mathrm{Sr}$ and $\mathrm{Al}_{4} \mathrm{Sr}$ phases. The occurrence of particles of hard intermetallic phases of $\mathrm{Sr}$ does not strengthen the alloy, but increases wear resistance. 
Fig. 6 The microstructure of the $\mathrm{Zn}-\mathrm{Al}$ alloy with $\mathrm{Sr}$ addition cooled with a rate of $0.1^{\circ} \mathrm{C} \mathrm{s}^{-1}$ : a bright field; $\mathbf{b}$ diffraction of the area in Fig. 5A a solution of the diffraction pattern $\mathrm{Al}_{4} \mathrm{Sr}$ phase, zone axis $[3 \overline{3} \overline{1}]$ (a)

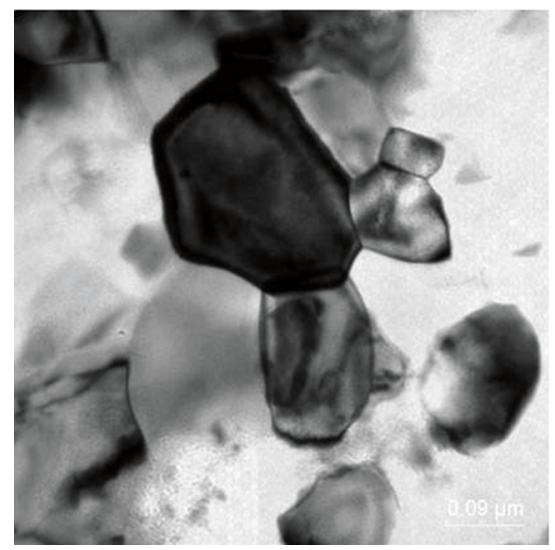

(b)

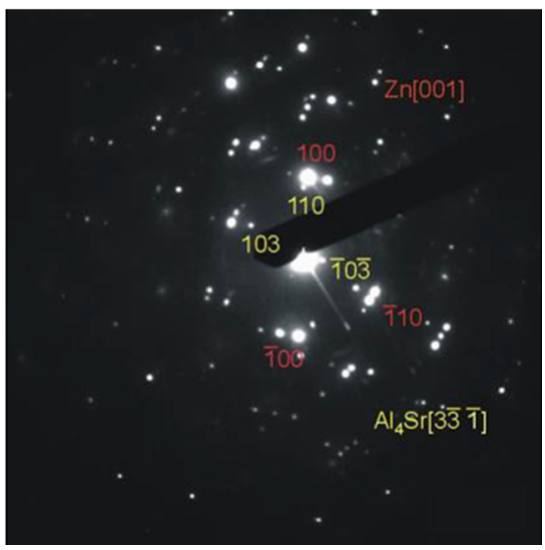

Fig. 7 Wear trace after the ballon-plate test for chosen alloys: a $\mathrm{Zn}-\mathrm{Al} ; \mathbf{b} \mathrm{Zn}-\mathrm{Al}(1 \mathrm{Sr})$
Table 4 Wear volume of the investigated alloys (a)

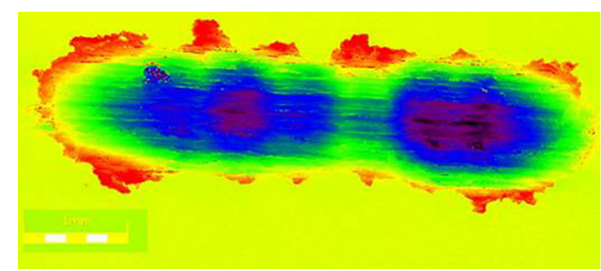

(b)

\begin{tabular}{llrc}
\hline Alloy type & Volume of the wear material & \multicolumn{2}{c}{ Volume difference compared to non-modified sample } \\
\cline { 3 - 4 } & $\mu \mathrm{m}^{3}$ & $\mu \mathrm{m}^{3}$ & $\%$ \\
\hline $\mathrm{Zn}-\mathrm{Al}$ & $142,706,639$ & 0 & 0.00 \\
$\mathrm{Zn}-\mathrm{Al}(1 \mathrm{Sr})$ & $132,924,458$ & $-9,782,182$ & -7.4 \\
\hline
\end{tabular}

\section{Conclusions}

The isothermal holding temperature of the liquid $\mathrm{Zn}$ alloy is essential due to the kinetics of crystallisation. The temperature of $700{ }^{\circ} \mathrm{C}$ causes the nucleation of the $\mathrm{Al}_{4} \mathrm{Sr}$ phase as the first phase followed by the $\alpha$ phase and eutectic. This results in a decrease in grain size of the microstructure, and hard phases with strontium increase the abrasion resistance of the alloy. However, $\mathrm{Zn}$ alloys should not be overheated, so the isothermal holding temperature of the liquid alloy is not recommended. It has been shown that the application of lower isothermal holding temperature $\left(450{ }^{\circ} \mathrm{C}\right)$ characteristic for this type of alloys causes the same changes in the material, i.e. the primary $\mathrm{Al}_{2} \mathrm{Sr}$ and $\mathrm{Al}_{4} \mathrm{Sr}$ phases provide the basis for heterogeneous nucleation and change the morphology of the structural components. Preliminary investigations, however, do not exclude the partial dissolution of minor $\mathrm{Al}_{4} \mathrm{Sr}$ phases and formation of the zinc phase of the $\mathrm{Zn}_{13} \mathrm{Sr}$ type. Investigations of the hypereutectic $\mathrm{Zn}-\mathrm{Al}-\mathrm{Cu}$ alloy modified with $10 \% \mathrm{Al}-\mathrm{Sr}$ master alloy allow to form the following conclusions:

- Preheating of the alloy at $450{ }^{\circ} \mathrm{C}$ for $300 \mathrm{~s}$ does not allow the complete diffusion of $\mathrm{Sr}$ to the solution, and the $\mathrm{Al}_{4} \mathrm{Sr}$ and $\mathrm{Al}_{2} \mathrm{Sr}$ phases present in the alloy are primary phases and can be the basis for the heterogeneous nucleation of the $\alpha$ phase $[11,12]$.

- Increase in the temperature to $700{ }^{\circ} \mathrm{C}$ causes crystallisation of the $\mathrm{Al}_{4} \mathrm{Sr}$ phase at $657.8^{\circ} \mathrm{C}$.

- Intermetallic phases with strontium increase the abrasion resistance by approx. $7.5 \%$ due to the occurrence of dispersive non-coherent intermetallic phases $\mathrm{Al}_{4} \mathrm{Sr}$ and $\mathrm{Al}_{2} \mathrm{Sr}$.

Acknowledgements This publication was financed by the Ministry of Science and Higher Education of Poland as the statutory financial grant of the Faculty of Mechanical Engineering SUT.

Open Access This article is distributed under the terms of the Creative Commons Attribution 4.0 International License (http:// 
creativecommons.org/licenses/by/4.0/), which permits unrestricted use, distribution, and reproduction in any medium, provided you give appropriate credit to the original author(s) and the source, provide a link to the Creative Commons license, and indicate if changes were made.

\section{References}

1. Adamczyk J. Equilibrium phase systems, solidification of metals and alloys. T. VII, ISSN 0208-9386, Ossolineum. 1984. (in Polish).

2. Yang LJ. The effect of casting temperature on the properties of squeeze cast aluminium and zinc alloys. J Mater Process Technol. 2003;140:391-6.

3. Yang LJ. The effect of solidification time in squeeze casting of aluminium and zinc alloys. J Mater Process Technol. 2007;192-193:114-20.

4. Osorio WR, Garcia A. Modeling dendritic structure and mechanical properties of $\mathrm{Zn}-\mathrm{Al}$ alloys as a function of solidification conditions. Mater Sci Eng A Struct. 2002;325:103-11.

5. Durman M, Murphy S. An electronmetallographic study of pressure die-cast commercial zinc-aluminium-based alloy ZA27. J Mater Sci. 1997;32:1603-11.
6. Krajewski WK, Buras J, Krajewski PK, Greer AL, Faerber K, Schumacher P. New developments of Al-Zn cast alloys. Mater Today Proc. 2015;2:4978-83.

7. Labisz K, Krupinski M, Pawlyta M, Matus K, Kremzer M, Dopierala K. High resolution TEM investigations and TDA analysis of zinc alloy with strontium addition. Acta Phys Pol A. 2016;130(4):823-6.

8. Closset B, Dugas H, Pekguleryuz M, Gruzleski JE. The aluminum-strontium phase. Diagr Metall Trans Sect A Phys Metall Mater Sci. 1986;17:1250-3.

9. Cordier G, Czech E, Schäfer H. Über eine Hochdruckmodifikation des SrAl2. Z Anorg Chem. 1982;37:1442-5.

10. Krajewski WK, Greer AL, Krajewski PK. Trends in developments of high-aluminium zinc alloys of stable structure and properties. Arch Metall Mater. 2013;58:845-7.

11. Krupińska B, Krupiński M, Rdzawski Z, Labisz K, Król M. Characteristic of cast $\mathrm{Zn}-\mathrm{Al}-\mathrm{Cu}$ alloy microstructure after modification. Arch Foundry Eng. 2014;14(4):77-82.

12. Krupinski M, Krupinska B, Rdzawski Z, Labisz K, Tanski T. Additives and thermal treatment influence on microstructure of nonferrous alloys. J Therm Anal Calorim. 2015;120(3):1573-83. 